\title{
ResearchArticle
}

\section{Study the relationship of Pleurotus florida with other Pleurotus sp. and fungal moulds}

\author{
R. L. Sharma and M. P. Thakur
}

\section{SUMMARY}

The present investigation on study the relationship of Pleurotus florida, with other Pleurotus sp. and fungal moulds was undertaken with the objectives to study the growth, population of substrate mycoflora associated and inhibition of P. florida, with other Pleurotus sp. and fungal moulds. In all the cases, the test fungus showed less mycelial growth while $P$. florida recorded maximum growth $(43.47 \mathrm{~mm})$ in dual culture with $P$. ostreatus followed by combination with $P$. flabellatus $(41.54 \mathrm{~mm})$. Regarding the population of mycoflora during different month, it was generally lower from November to March and August to September when the growth of P. florida was profuse and abundant due to fovourable prevailing climatic conditions. However, the population of mycoflora was comparatively higher during April to July with rise in temperature, fall in relative humidity and unfavourable conditions for development of mushroom mycelium and fruiting. The results also revealed that all the isolated fungi had relatively faster rate of growth than P. florida on potato dextrose agar medium. The rate of growth in Rhizopus sp. was more followed by Aspergillus niger, A. flavus and Trichoderma viride. However, the rate of growth was comparatively less in Rhizoctonia sp. Maximum inhibition in radial growth of P. florida was recorded with Rhizopus sp. (70.45\%) followed by A. niger (65.90\%) and A. flavus (63.63\%). However, the inhibition of growth of P. florida was minimum in Rhizopus sp. (29.51\%).

Key Words : Relationship of Pleurotus florida, Pleurotus sp., Fungal moulds

How to cite this article : Sharma, R.L. and Thakur, M.P. (2019). Study the relationship of Pleurotus florida with other Pleurotus sp. and fungal moulds. Internat. J. Plant Sci., 14 (1): 14-18, DOI: 10.15740/HAS/IJPS/14.1/14-18, Copyright@ 2019: Hind AgriHorticultural Society.

Article chronicle : Received : 10.10.2018; Revised : 04.12.2018; Accepted : 13.12.2018

\section{$\longrightarrow$ MEMBERS OF THE RESEARCH FORUM}

Author to be contacted :

R. L. Sharma, Krishi Vigyan Kendra (I.G.K.V.), Raipur (C.G.) India

Email : ramlaxmansharma@yahoo.com 